\title{
Fluorescent Polymer Nanoparticles for Cell Barcoding in Vitro and in Vivo
}

Bohdan Andreiuk, Andreas Reisch*, Marion Lindecker, Gautier Follain, Nadine Peyriéras, Jacky G. Goetz, Andrey S. Klymchenko*

B. Andreiuk, Dr. A. Reisch, M. Lindecker, Dr. A. S. Klymchenko Laboratoire de Biophotonique et Pharmacologie,

UMR 7213 CNRS, Faculté de Pharmacie, Université de Strasbourg, 74, Route du Rhin, BP 60024, 67401 Illkirch, France.

E-mail: andrey.klymchenko@ unistra.fr ; reisch@unistra.fr.

G. Follain, Dr. J. G. Goetz

MN3T, Inserm U1109, LabEx Medalis, Fédération de Médecine Translationnelle de Strasbourg (FMTS), Université de Strasbourg, Strasbourg, 67000, France

Dr. N. Peyriéras

CNRS USR3695 BioEmergences, Avenue de la Terrasse, 91190 Gif-sur-Yvette, France

Keywords: dye-loaded polymer nanoparticles, optical coding, long-term cell tacking, fluorescence microscopy, zebrafish 


\begin{abstract}
Fluorescent polymer nanoparticles for long-term labeling and tracking of living cells with any desired color code are developed. They are built from biodegradable PLGA polymer loaded with cyanine dyes (DiO, DiI and DiD) with the help of bulky fluorinated counterions, which minimize aggregation-caused quenching. At the single particle level these particles are ca 20 -fold brighter than quantum dots of similar color. Due to their identical 40-nm size and surface properties, these nanoparticles are endocytosed equally well by living cells. Mixing nanoparticles of three colors in different proportions generates a homogeneous RGB barcode in cells, which is transmitted through many cell generations. Cell barcoding is validated on seven cell lines (HeLa, KB, 293T, CHO, RBL, U97 and D2A1), 13 color codes, and it enables simultaneous tracking of co-cultured barcoded cell populations for $>2$ weeks. It is also applied to studying competition among drug-treated cell populations. This technology enabled six-color imaging in vivo for (1) tracking xenografted cancer cells and (2) monitoring morphogenesis after microinjection in zebrafish embryos. In addition to a robust method of multi-color cell labeling and tracking, our work suggests that multiple functions can be co-localized inside cells by combining structurally close nanoparticles carrying different functions.
\end{abstract}




\section{Introduction}

The current trend in nanotechnology for biological applications is implementation of multiple functions within the same nanoparticle (NP). One should mention multimodal NP probes that enable simultaneous use of several imaging modalities, such as magnetic, X-ray and/or fluorescence. ${ }^{[1]}$ Another example is co-encapsulation of a drug with an imaging agent, which enables developing highly promising tools for theranostics. ${ }^{[1 b, 2]}$ Finally, in optical imaging, which is currently undergoing remarkable growth, multiple colors are included within the same particles, thus providing them with unique color fingerprints (barcodes) for multiplex detection. ${ }^{[3]}$ However, implementation of multiple functions within the same NP requires complicated synthetic protocols, which have to be revalidated for the whole system once a single function is changed, added, or removed. Moreover, these protocols do not always allow achieving high reproducibility of nanoparticle properties, so that the important challenges related to cost, effectiveness and toxicity of these NPs in the biomedical context are still to be addressed. ${ }^{[4]}$ A totally different approach is to implement multiple functions separately into different NPs of practically identical characteristics, and then to combine them together to achieve a desired multifunctional effect in biological samples. In this case, the similar size and surface properties of the NPs ensure their identical delivery in biological samples so that multiple functions of these NPs are co-localized. This approach could be realized within optical modality, where structurally close NPs of different colors, undergoing identical delivery into live cells, could generate any desired barcode for long-term cell tracking in vitro and in vivo, something that has not been realized to date.

Long-term fluorescence staining of living cells in multiple colors is of high importance for tracking different cell populations in vitro and in vivo, and in this way helps to address key questions in cancer research, cell differentiation, cell therapy, regenerative medicine, embryogenesis. ${ }^{[5]}$ However, due to the relatively broad absorption and emission bands of organic dyes, fluorescent nanoparticles and fluorescent proteins standard fluorescent microscopy can distinguish only 4-5 individual colors. A recently proposed concept, named "Brainbow", ${ }^{[6]}$ overcomes this problem by using RGB optical (color) coding, where a practically unlimited number of barcodes can be generated by co-expressing blue, green and red fluorescent proteins in a stochastic and thus unique combination. This method has been successfully used for visualizing neuronal networks in vitro and in vivo ${ }^{[7]}$ and cellular organization and development in small animals, ${ }^{[8]}$ and was recently proposed for stem cells ${ }^{[9]}$ and cancer research. ${ }^{[10]}$ However, color coding of living cells without their genetic modification is underexplored. To develop such a method, several fundamental problems have to be addressed: (i) long-term cell staining should be achieved; (ii) this implies that staining should be sufficiently bright despite multiple cellular divisions; (iii) the individual colors should be stable and 
well resolved, so that each color code and thus each cell population could be recognized even after several weeks; (iv) the staining should not produce toxic effects, especially in the view of long-term studies. Organic dyes, such as hydrophobic cyanine dyes (DiO, DiI, DiR and PKH family) and the specially designed CellTracker ${ }^{\mathrm{TM}}$ and CellTrace ${ }^{\mathrm{TM}}$ families (CFSE, CM-DiI, CMTMR, etc) can be used for long-term cell staining. ${ }^{[11]}$ However, the staining generally remains for only about 3 days. ${ }^{[12]}$ Moreover, no reports showed that these dyes could be used in combination to generate multiple colors, as it is done by Brainbow using fluorescent proteins. New possibilities emerge with fluorescent nanoparticles. ${ }^{[4 \mathrm{~b}, 13]}$ Recent reports described long-term staining using NPs based on aggregation induced emission of dyes, ${ }^{[14]}$ although their application for RGB color coding has not been shown. Studies of color coding using nanoparticles were mainly focused on multiplex detection of biomolecules in solution. ${ }^{[15]}$ The only attempts to barcode living cells using NPs were performed with quantum dots (QDs). ${ }^{[16]}$ However, due to the stochastic nature of their internalization, ${ }^{[17]}$ cell labeling by QDs of three different colors generated randomly distributed color codes within the same population of cells. ${ }^{[16 \mathrm{~b}]}$ At the moment, there is no method for exogenous cell labeling that can generate in a whole cell population a defined RGB barcode readable directly by fluorescence microscopy. One solution is to use fluorescent dye-loaded polymer nanoparticles (NPs), which attracted attention due to their extreme brightness (>10 brighter than QDs), color variability, biodegradability and low toxicity. ${ }^{[18]}$ Significant efforts have been done to design multi-color dye-loaded polymer nanoparticles through encapsulation of multiple dyes within the same NPs, which ensures cascade FRET and multiband emission. ${ }^{[3 a, 19]}$ One of these systems was applied for RGB color coding, where two cell populations were distinguished without long-term measurements. ${ }^{[3 a]}$ Recently, we developed 40-nm polymer NPs based on the biodegradable polymer poly(lactic-co-glycolic acid) (PLGA). ${ }^{[20]}$ To achieve high dye loading with excellent brightness, we combined a hydrophobic cationic dye, octadecyl-rhodamine, with bulky fluorinated counterions. These NPs showed very fast internalization into cells by endocytosis, thus providing efficient cellular labeling. ${ }^{[20]}$ We hypothesized that the counterion approach could be expanded to other cationic dyes, such as cyanines, so that we could generate NPs bearing three well-separated absorption/emission bands. Then, if these NPs are of similar size and surface properties, they may present identical internalization inside cells, so that their co-incubation with cells in different proportions could generate labeled cells of any desired color far beyond the commonly used three colors. Presently, we successfully realized this hypothesis, where the obtained ultrabright NPs of three different colors could label living cells with at least 13 different RGB barcodes. These color codes are transmitted through many cell generations, so that the cells could be tracked in culture for $>2$ weeks. In addition, we showed that such barcoded cells can be easily tracked in living animals such as zebrafish embryos. 


\section{Results}

\subsection{Preparation and characterization of nanoparticles.}

To obtain fluorescent polymer NPs of small size, we used our recently developed protocol of charge-controlled nanoprecipitation, ${ }^{[20-21]}$ where a diluted solution of a polymer bearing one charged group per chain and a dye in an organic solvent is rapidly added into aqueous media. In case of PLGA, bearing one negatively charged carboxylate at the polymer terminus, NPs of 35-40 nm diameter can be obtained. To generate NPs of three distinct colors we selected cyanine dyes, which are known to exhibit sharp absorption and emission bands. For successful encapsulation inside polymer NPs, the dyes should be hydrophobic, so that they will co-precipitate together with the polymer. Hence, we selected cyanine derivatives bearing two octadecyl chains: DiO, DiI and DiD (Figure. 1A). The choice of the counterion was of high importance for obtaining small NPs. While the use of small inorganic counterion (e.g. chloride or perchlorate) led to a strong increase in NP size, using bulky hydrophobic tetraphenylborate counterions (F0, F5 and F12, Figure 1A) led to a minimal dependence of the size of NPs on the dye loading (Figure 1C, Supplementary Tables 1 and 2). The best results were obtained with the fluorinated counterions F5 and F12, showing that the super-hydrophobicity of fluorous compounds ${ }^{[22]}$ plays a key role in efficient encapsulation of cationic dyes into polymer NPs. Increase in the dye loading produced a systematic decrease in the fluorescence quantum yield (QY) of NPs (Figure 1D) and broadening of absorption bands (Figure S1-3), which are clearly related to aggregation caused quenching (ACQ) ${ }^{[23]}$. However, these unwanted effects were minimized by using the fluorinated counterions F5 and F12 (Figure 1D, Figure S1-3). The most efficient in this respect was the largest counterion F12, as the QY values were the highest for most of the formulations, notably in the case of Cy5, where F12 allowed obtaining QYs of $14 \%$ even at $20 \mathrm{mM}$ loading. 


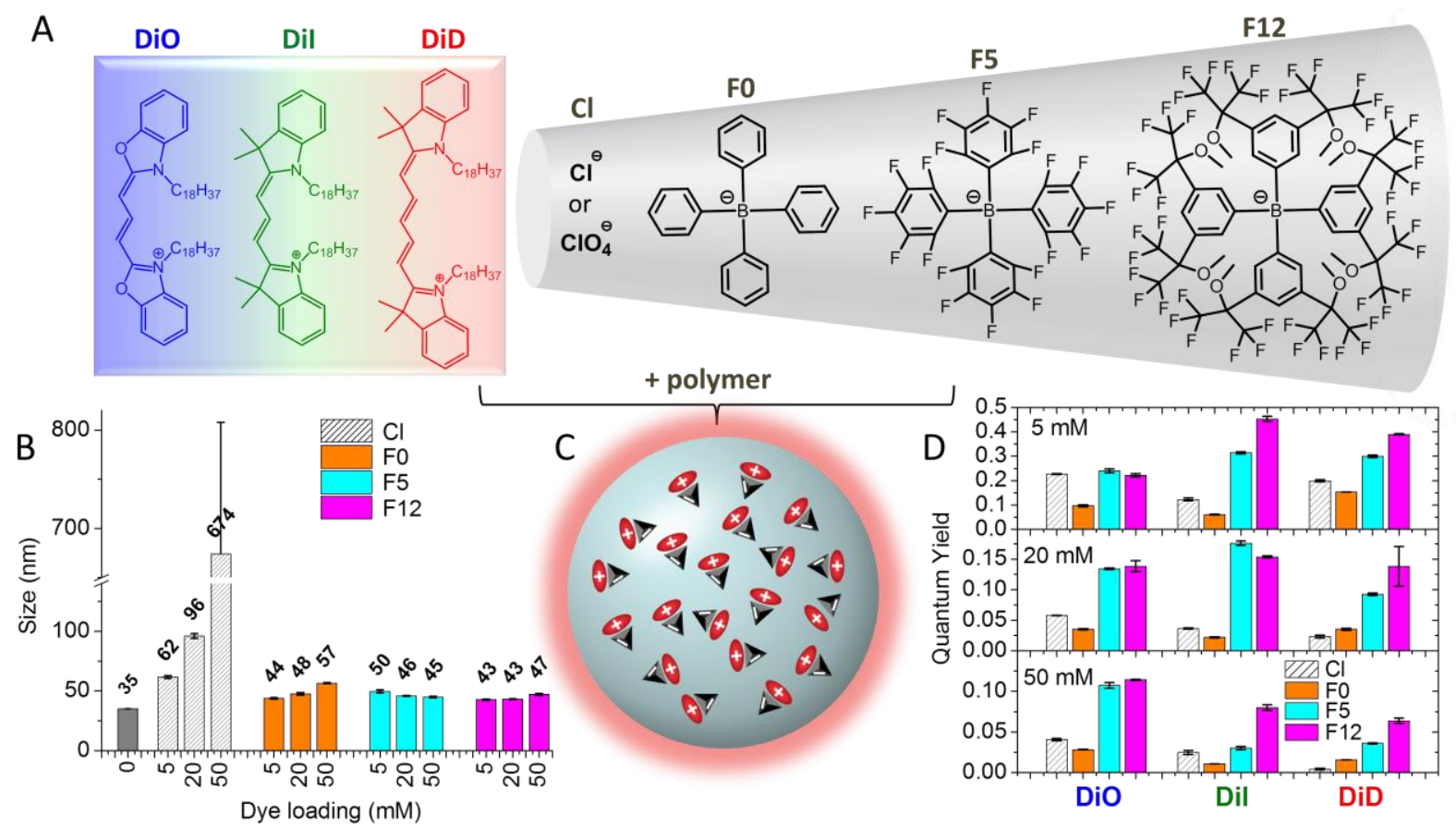

Figure 1. Polymer NPs loaded with cyanine dyes using different counterions. (A) Chemical structures of cationic cyanine dyes (blue, green and red) and their counterions (in black). (B) Effect of dye loading on the hydrodynamic diameter of NPs doped with DiO bearing inorganic (perchlorate) or different bulky organic counterions (F0, F5 and F12). (C) Schematic presentation of dye-loaded polymer nanoparticles. (D) Fluorescent quantum yields of NPs loaded at different concentration with three cyanine dyes: role of counterions for preventing self-quenching. The error bars are standard error of the mean $(n=3)$.

Based on the obtained results we selected $20 \mathrm{mM}$ loading of cyanine dyes with the F12 counterion and further characterized the obtained NPs in detail. Absorption spectra of these NPs presented maxima at 488, 553 and $651 \mathrm{~nm}$ (Figure 2A), which corresponded well to those of DiO, DiI and DiD dyes in methanol (Figure S1-3) and matched the most common laser lines at 488, 561 and 640 $\mathrm{nm}$. The emission bands were rather sharp for DiI-F12 and DiD-F12 dye loaded NPs (Figure 2A), similar to those in methanol (Figure S1-3), which confirmed minimal aggregation of dyes at this high loading. Despite a broader emission spectrum of DiO-F12 NPs, it is clear that, using appropriate excitation wavelengths and emission filters, it would be possible to detect each of these three types of NPs, without cross-talk in the detection (Figure 2A). Electron microscopy revealed that, independently of the loaded dye, NPs displayed the same size and spherical structure (Figure 2B,C). Moreover, the dye-loaded NPs showed practically the same zeta-potential of around $-40 \mathrm{mV}$ as the corresponding blank NPs (Figure 2B). Therefore, we can conclude that encapsulation of dyes 
did not alter the surface properties of the NPs. Thus, we obtained fluorescent NPs of three different colors presenting the same size and surface properties. In wide-field fluorescence microscopy all three types of NPs appeared as bright fluorescent dots (Figure 2D). Remarkably, the brightness of DiI-F12 NPs was 22-fold larger than that of QDs of similar color (QD585, Figure 2E).
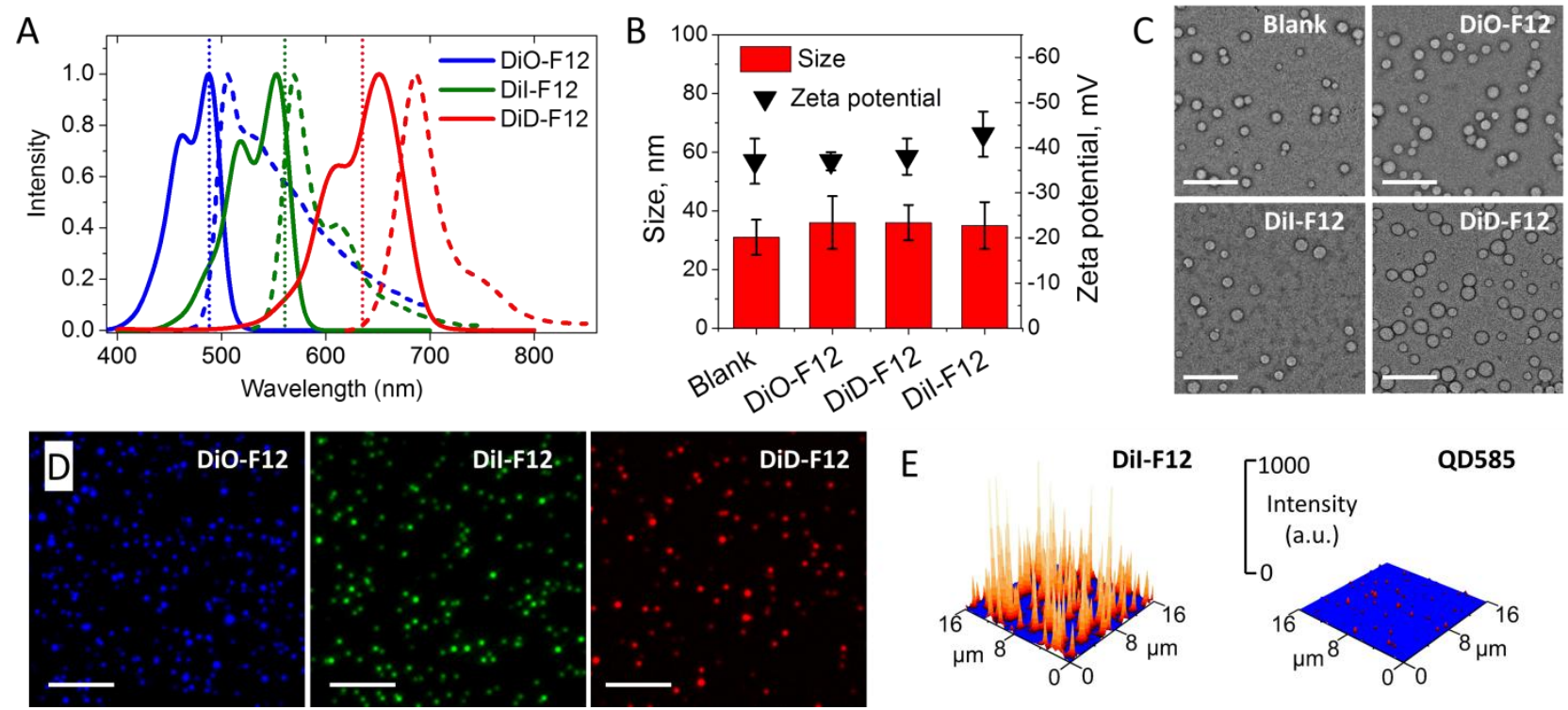

Figure 2. Properties of the three types of NPs loaded with the three cyanine dyes DiO, DiI and DiD and the F12 counterion at $20 \mathrm{mM}$. (A) Normalized absorption and fluorescence spectra of cyanineloaded polymer NPs. (B) Diameter based on TEM images and zeta potential of these NPs. The error bars are standard error of the mean $(n=3)$. (C) Electron microscopy of blank and dye-loaded NPs. Scale bar is $200 \mathrm{~nm}$. (D) Wide-field fluorescence microscopy images of dye-loaded NPs. Scale bar is $5 \mu \mathrm{m}$. Illumination power was $1 \mathrm{~W} \mathrm{~cm}^{-2}$ at $488 \mathrm{~nm}$ (DiO-F12), $532 \mathrm{~nm}$ (DiI-F12) and $645 \mathrm{~nm}$ (DiD-F12). (E) 3D representation of fluorescence image of DiI-F12 NPs in comparison to quantum dots QD585. Excitation wavelength was $532 \mathrm{~nm}$.

\subsection{Cell labeling by NPs.}

For labeling, the cells were incubated with NPs for $3 \mathrm{~h}$ at $37^{\circ} \mathrm{C}$, followed by rinsing and transfer to chambered microscope slides. Then, the cells were imaged using three excitation/detection channels (displayed in blue, green, and red) corresponding to the DiO-F12, DiI-F12, and DiI-F12 NPs, using similar laser powers and detection sensitivities. In order to delimit the cells, they were additionally stained with the violet membrane probe F2N12SM ${ }^{[24]}$ (displayed in grey). In total, we tested our NPs on six cell lines: HeLa (studied the most extensively), KB, 293T, U87, RBL and CHO. Fluorescence microscopy revealed homogeneous staining of virtually all imaged cells (Figure 3A), and this phenomenon was observed for the three types of NPs in all six cell lines (Figure S4 and 5). 
Moreover, the signal from the labeled cells was observed only in the corresponding blue, green or red channel (Figure 3A), indicating minimal cross-talk of the channels. Finally, analysis of fluorescence images revealed similar intensities of the cells labeled with all three types of NPs (Figure S6). Flow cytometry analysis confirmed the observed similar staining of cells by NPs of different colors and showed that practically all cells were labeled (Figure S7). These results suggest that internalization of NPs is independent of the encapsulated dyes, in agreement with invariant sizes and surface properties of these NPs.

A closer look in the case of KB and HeLa cells (Figure 3B,C), revealed that after $24 \mathrm{~h}$ the NPs were mainly located in the perinuclear regions in form of bright spots. This is in agreement with an endosomal entry of these NPs, as we have shown earlier for the same type of PLGA NPs loaded with a rhodamine dye. ${ }^{[20]}$ The observed high contrast between the perinuclear regions and the rest of the cells suggested minimal dye leaching from NPs even after $24 \mathrm{~h}$ of incubation. By contrast, when NPs were loaded with $\mathrm{DiO}$ perchlorate (i.e. without hydrophobic counterion), the images showed a diffuse fluorescence throughout the cell, probably due to leaching of the poorly encapsulated dye from the NPs (Figure S8).

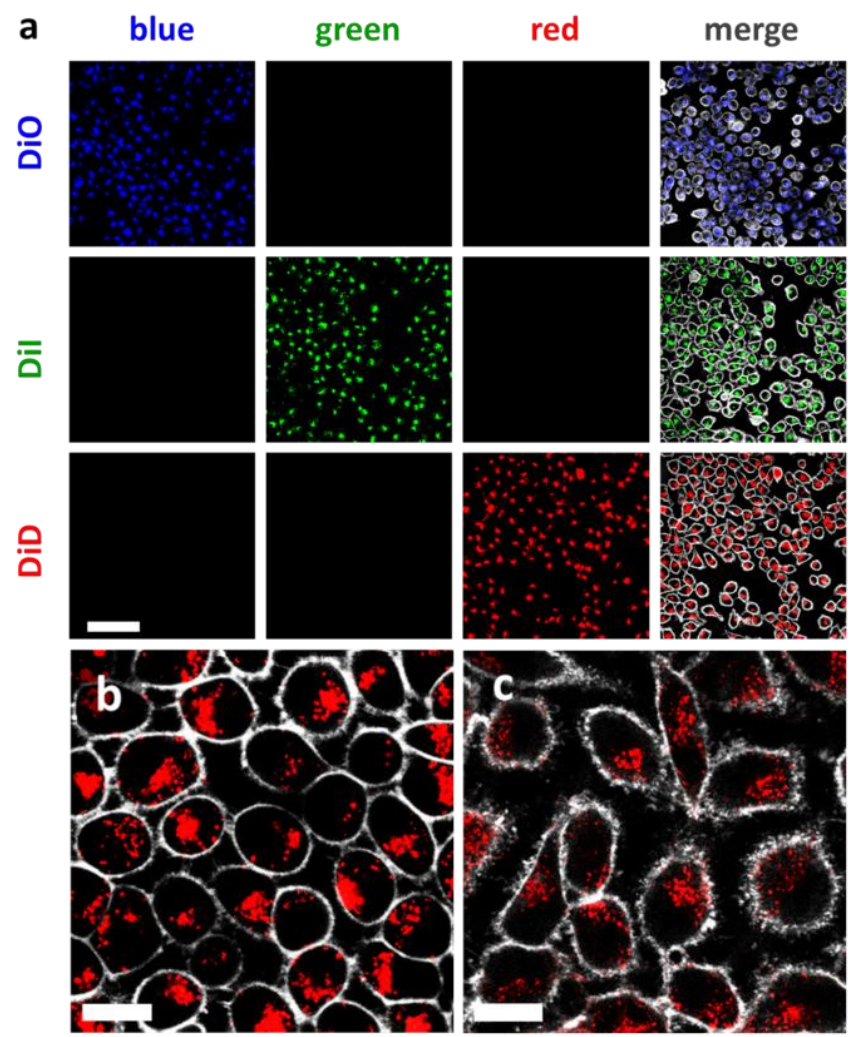

Figure 3: Fluorescence micrographs of cells incubated for $3 \mathrm{~h}$ with nanoparticles. (a) KB cells labeled with DiO-F12 (top row), DiI-F12 (middle row), and DiD-F12 (bottom row) NPs. The images obtained in the different channels are shown (blue, green and red). Merged images from all 
three channels are shown on the right; membrane staining is shown in grey. A 20x objective was used; scale bar is $100 \mu \mathrm{m}$. (b,c) Localization of DiD-F12 NPs in KB (b) and HeLa (c) cells. The membrane was labeled with F2N12SM. Before imaging, the cells were incubated with NPs for 3h, rinsed, transferred into microscopy chambers and then incubated for $24 \mathrm{~h}$. A $63 \mathrm{x}$ objective was used; scale bar is $20 \mu \mathrm{m}$.

We then estimated the number of NPs per cell using two methods: (i) The fluorescence emission of labeled cells was measured in suspension using a fluorometer and compared to the emission of solutions of the corresponding NPs of known concentrations (Figure S9). (ii) The intensities of total fluorescence emission per cell were determined from confocal microscopy images at low magnification (20x objective) and compared to that of standard $200 \mathrm{~nm}$ beads (Figure S10). The two methods gave remarkably close results, respectively, 9400 and 10500 NPs per HeLa cell $24 \mathrm{~h}$ after labeling with $0.15 \mathrm{nM}$ of DiI-F12 NPs (0.002 g/L of polymer). The analyzed per cell fluorescence revealed a relatively narrow distribution of the number of NPs per cell (Figure S10). Increasing the particle concentration to 0.45 and $1.5 \mathrm{nM}$ (corresponding to 0.006 and $0.02 \mathrm{~g} / \mathrm{L}$ of polymer), led to an increase in the labeling intensity (Figure S11A), corresponding to 23000 and 45000 NPs per cell.

Finally, according to MTT assays, the NPs did not show significant cytotoxicity after 72h of incubation with HeLa cells at concentrations more than 10 times those used for labeling (Figure S12). Thus, our NPs can internalize equally well into all cells, independently of the encapsulated dye and display minimal crosstalk between the RGB channels, high stability and low toxicity over extended periods of culture.

\subsection{RGB barcoding of living cells.}

The described unique properties of our NPs gave the possibility to label cells by a variety of color codes simply by incubating the cells with different mixtures of these NPs (Figure 4). For example, to achieve an orange labeling, we mixed DiI-F12 NPs and DiD-F12 NPs in a 0.25 to 0.75 ratio in Opti-MEM, followed by incubation for $3 \mathrm{~h}$. After $24 \mathrm{~h}$ of culture the labeled cells showed an intensity of the DiD channel about three times that of the DiI channel, and negligible signal in the DiO channel (Figure 4B), so that the merged images yielded an orange color for all the imaged cells. Applying this procedure to different mixtures of NPs resulted in cell populations labeled homogeneously with 13 clearly distinguished colors (Figure 4C), while keeping all the instrumental 
and analysis setting identical. The colors of the individual cells were then analyzed quantitatively. Owing to the perinuclear localization of the NPs, each labeled cell appeared as a separate region of high density of dots, which facilitated greatly an automated image analysis using an ImageJ macro (Supplementary file 1). The measured relative intensities of the three channels provided RGB barcodes for each cell, which were then represented in a ternary diagram of an RGB color triangle (Figure 4D). Analysis of over 2000 cells, showed 13 well-separated populations, which implies robust color coding of live cells by at least 13 different barcodes. It should be noted that incubation of cells with a simple mixture of dyes (DiI and DiD) without nanoparticles resulted rather heterogeneous color code (Figure S13). The latter could be explained by very poor solubility of these dyes in water, so that the aggregates of these dyes in water do not provide as homogeneous cell staining as PLGA NPs loaded with these dyes.

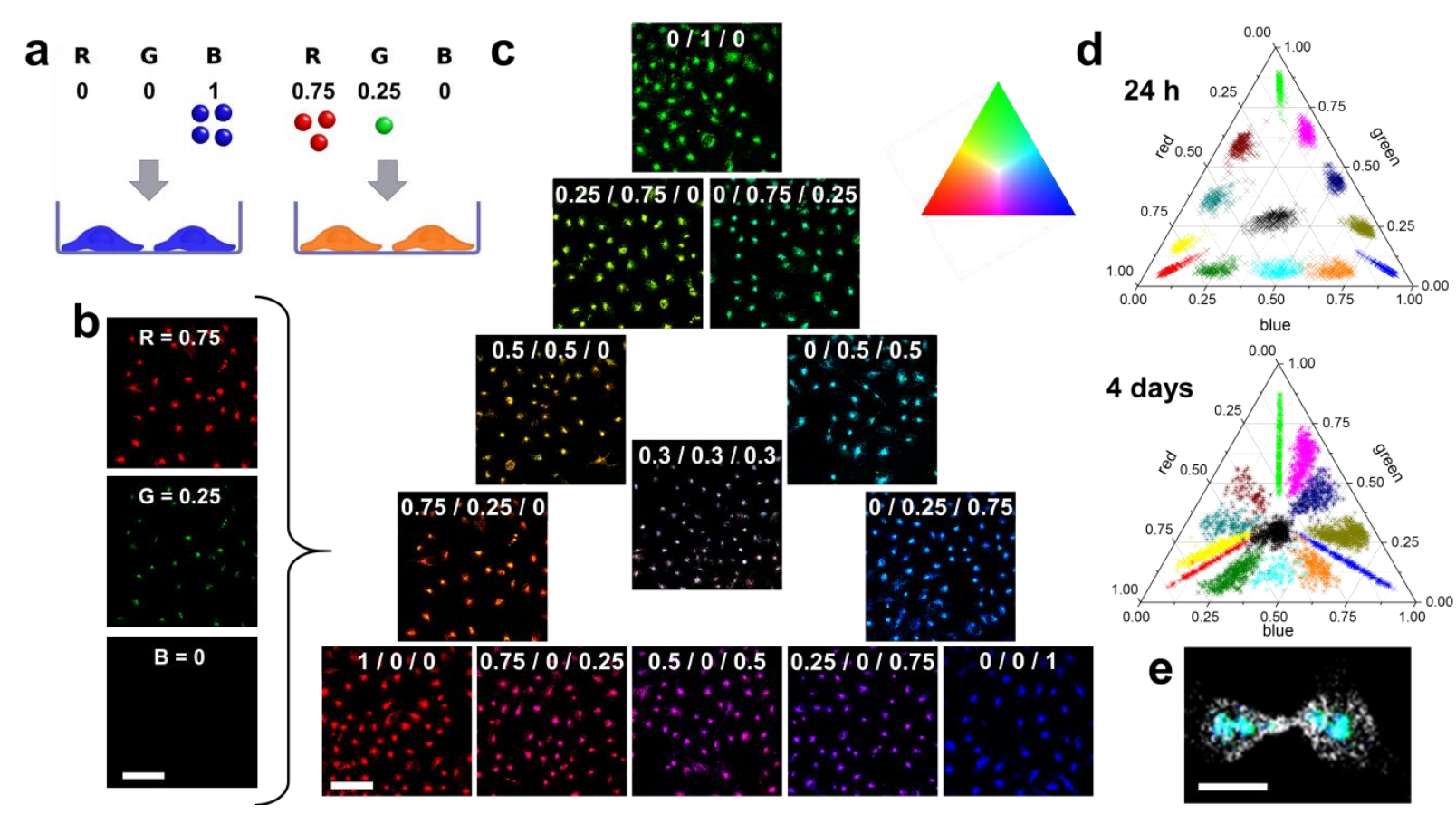

Figure 4. Multi-color labeling of HeLa cells. (a) Principle of cell color coding by NPs. (b) Example of cells labeled with orange: the images on the left show the three channels, the single image in the color triangle corresponds to the superposition of the three. (c) Images of cells after labeling with the different NP mixtures (13 colors). Scale bar is $100 \mu \mathrm{m}$. (d) Representation of the relative intensities of DiO (blue), DiI (green) and DiD (red) channels of individual cells in a ternary diagram at 1 and 4 days after labeling with 13 colors. The relative intensities were determined for about 200 cells per condition. Only the basic colors red, green, and blue are represented in these colors, all other colors are false colors in order to facilitate the distinction of adjacent colors. (e) Confocal image of selected dividing cell. 


\subsection{Transmission of RGB barcode to daughter cells.}

When HeLa cells labeled with different colors were cultured separately for longer periods, the color of each cell population was preserved, so that 13 colors remained easily distinguishable at 4 days (lower part of Figure 4D) and even at 8 days (Figure S14) after labeling. However, the decrease in the intensity of the signal produced some displacement of the color codes towards the center of the color triangle (Figure 4D). The preservation of the colors of cell populations after such long periods requires the NPs of different colors to be transmitted to the daughter cells in equal proportions. Indeed, in the observed cases of dividing cells (Figure 4E and Figure S15), both daughter cells displayed very similar fluorescence intensities and identical RGB barcodes. On the other hand, this implies that the mean fluorescence intensity of individual cells should decrease 2-fold after each division, which ultimately limits the overall time over which RGB barcodes were detectable. Consistently, the mean number of NPs per cell, as determined from microscopy, was 10500 after one day, 3300 after three days and 600 after seven days. Taking day one as the first cell generation, we could estimate that on day three and seven, we observed 2.7th and 5th generation of HeLa cells, which is a reasonable division rate (about 0.8 times per $24 \mathrm{~h}$ ).

\subsection{Distinguishing mixed populations of cells by color.}

When three cell populations labeled with NPs of different colors were mixed together, they could be easily distinguished after 1 day and even after 14 days of co-culture (Figure 5A,B). This result implied the cells did not exchange their internalized NPs and thus did not mix the colors. The color mixing was also not observed for higher NP concentration $(0.45 \mathrm{nM})$, which enabled observation of distinct cell populations even after 19 days (Figure S16). However, at the highest used concentration $(1.5 \mathrm{nM})$ the color mixing was detectable already after 24h (Figure S11B), which shows the upper concentration limit of this method. Then, we mixed seven populations of barcoded cells and after 4 days all of them were easily distinguishable both visually (Figure 5C) and as distinct regions in the color triangle (Figure S17), which should enable their automatized identification. Strikingly, our method also worked to distinguish 13 barcoded cell populations cocultured at least for $24 \mathrm{~h}$ (Figure S18).

We then applied our labeling method to barcode 6 different cell lines: HeLa, KB, embryonic kidney (293T), astrocytoma (U87), rat basophilic leucemia (RBL) and Chinese hamster ovary (CHO) cells. These cell lines were labeled with 6 different RGB barcodes and then either incubated separately or together by mixing in equal numbers for $24 \mathrm{~h}$ before imaging. Within the individual cell lines the applied barcode was identical in all imaged cells. In the mixture of cell lines, each cell type could be easily recognized by its color code as well as by its expected morphology (Figure 5D, Figure S19). 


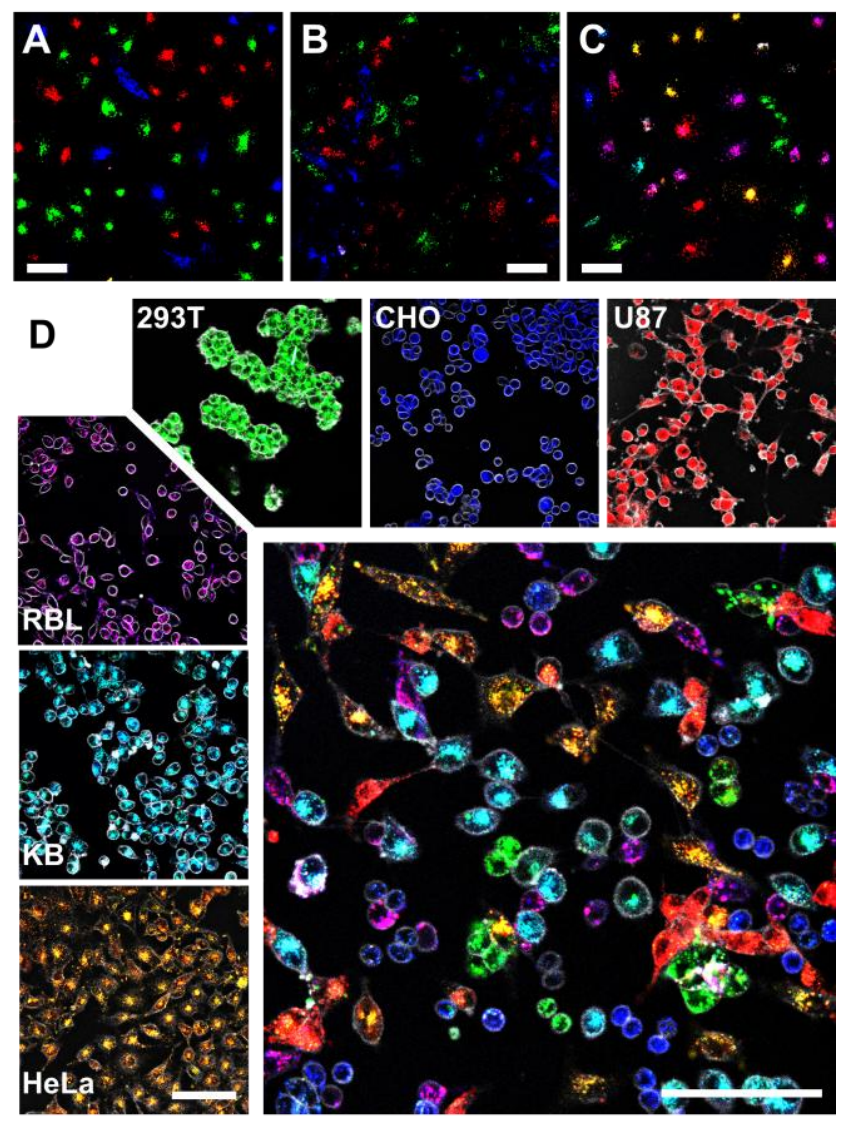

Figure 5. Co-culture of mixed RGB barcoded cell populations. (A,B) Confocal image of a mixture of three cell populations labeled with the three different NPs, respectively, 1 day (A) and 14 days (B) after labeling. Scale bar is $60 \mu \mathrm{m}$. (C) Confocal image of a mixture of seven cell populations of different colors four days after labeling. (D) The large micrograph shows a confocal image six cell types (HeLa, KB, 293T, U87, RBL, and CHO) mixed and co-cultured for $24 \mathrm{~h}$. Each cell type was labeled with an RGB barcode (orange, cyan, green, red, magenta and blue, respectively), also shown separately in the smaller images. Images are superpositions of the three NP channels with identical settings and of the membrane channel in gray. Scale bar is $100 \mu \mathrm{m}$.

\subsection{Competition among mixed cell populations after drug treatment.}

Finally, we used this method to distinguish the behavior of HeLa cells that underwent different doxorubicin treatments in direct competition for adhesion to the surface. Six populations of HeLa cells, where individual color corresponded to the level of doxorubicin treatment, were seeded in chambered microscope slides for $4 \mathrm{~h}$ and then imaged at different heights from the surface. (Figure S20). We found that non-treated cells in green had an approximately equal relative distribution throughout the three imaged z-planes. However, HeLa cells that had undergone a doxorubicin treatment at low concentration (magenta) were significantly more present close to the surface and 
showed a more surface-spread morphology. By contrast, those treated with intermediate concentrations (blue) were relatively more abundant further away from the surface and showed rather rounded shapes at the surface. Higher doxorubicin concentrations decreased significantly the cell fraction at all studied distances from the surface, probably because of fast cell death and aggregation (Figure S21).

\subsection{Multi-color tumor cell tracking in living animals.}

We then applied our color-coding approach to the tracking of tumor cells (D2A1, murine mammary carcinoma cells) directly in a living animal. To this end, six cell populations of tumor cells were labeled by distinct RGB barcodes of our NPs (Figure 6A) and then injected in the duct of Cuvier of zebrafish embryos (2 days post-fertilization, $2 \mathrm{dpf}$ ) and imaged 3 hours post-injection (3 hpi). Single cells and clusters of injected tumor cells can be found in the caudal plexus regions of the zebrafish embryo and are easily distinguishable based on their color (Figure 6B-D). Importantly, according to the images in 3 channels (Figure 6D) and the merged image (Figure 6B) all six colors are clearly defined without appearance of other colors (except cases of cell overlap). This means that the RGB barcode is well preserved inside the cells without leakage in vivo. 

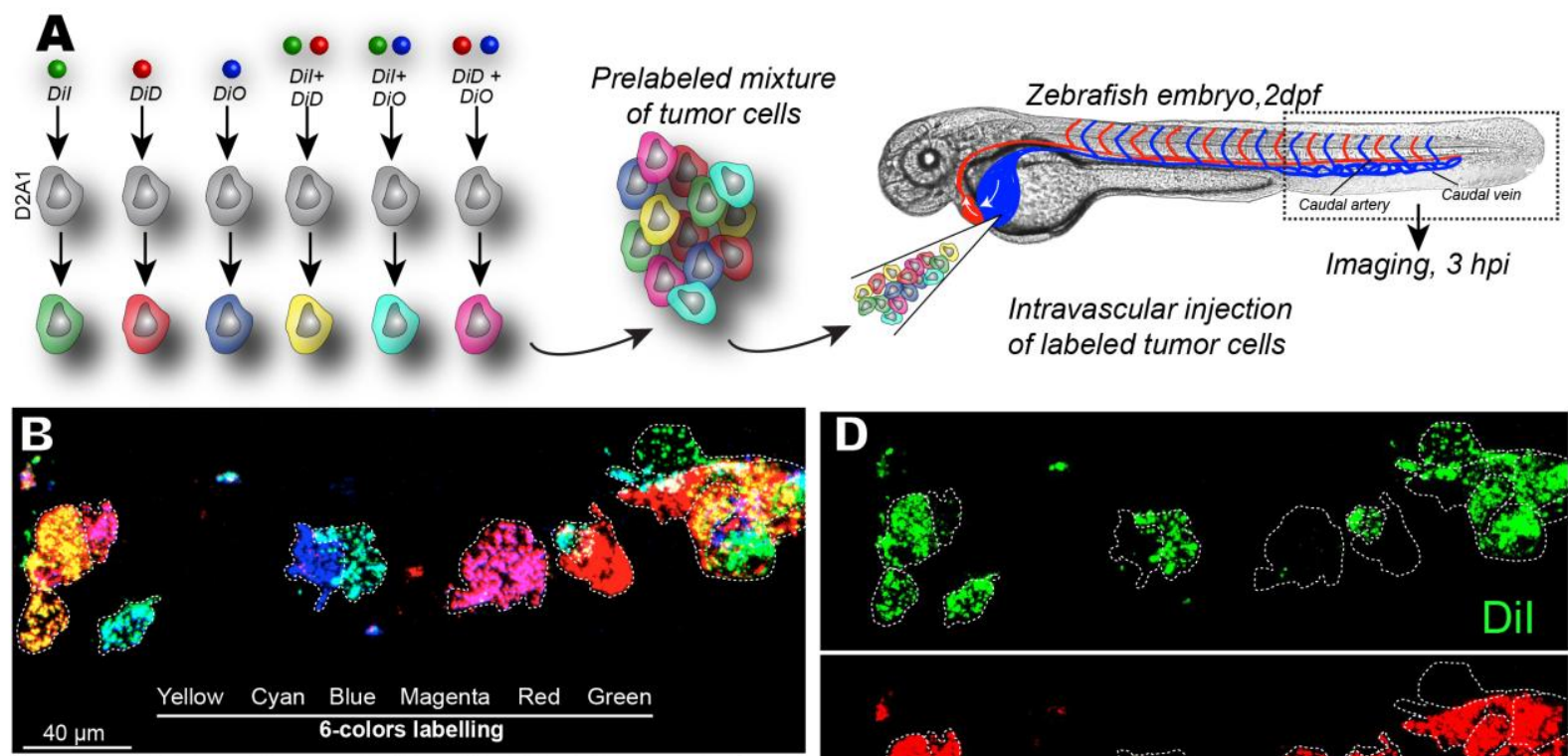

Intravascular injection of labeled tumor cells
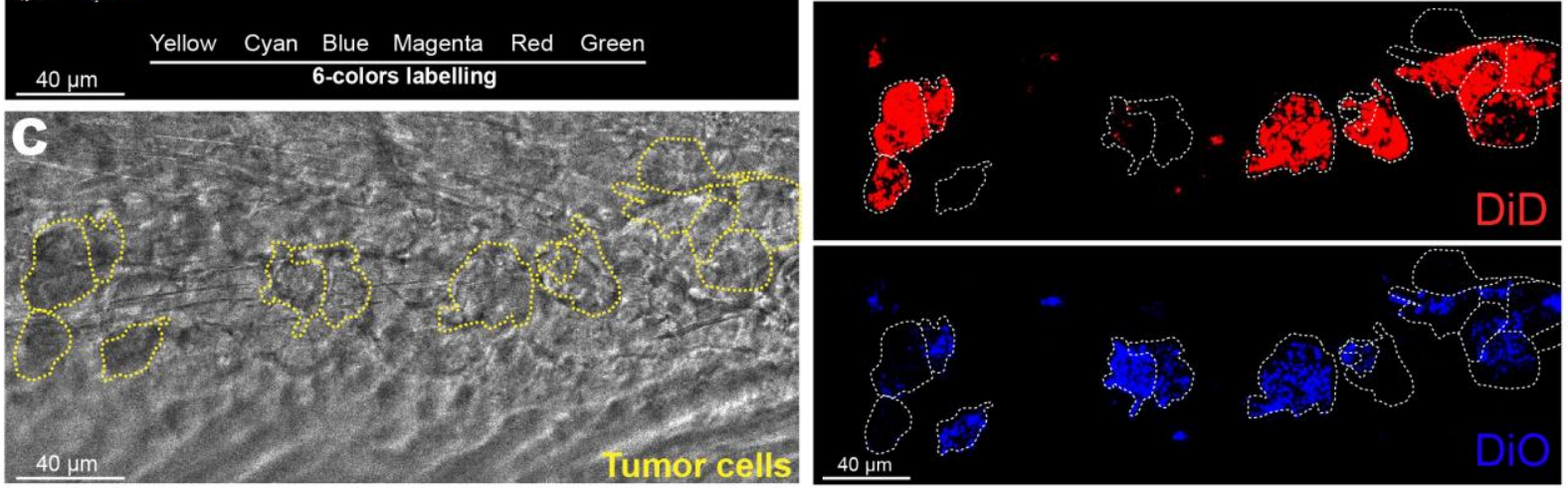

Figure 6. Tracking RGB barcoded cancer cells in zebrafish embryo. (A) Experimental design: Six batches of D2A1 cells were labeled with fluorescent NPs generating RGB barcodes (green, red, blue, yellow, magenta and cyan). Labeled cells were then mixed and injected intravascularly in 2 dpf zebrafish embryos. (B-D) Tumor cells that arrested in the vasculature are imaged at $3 \mathrm{hpi}$, in the caudal plexus region of the zebrafish embryo. Clusters and individuals cells can be found and distinguished based on their color.

\subsection{Cell tracking in the developing embryo.}

We further investigated the usefulness of our cell-labeling technology for developmental studies using zebrafish embryos. To do so, solutions of our NPs and NP mixtures were injected directly into the cytoplasm of distinct cells at the four- or eight-cell stage (Figure 7). Using this procedure the NPs distributed homogeneously throughout the cytoplasm of the injected cells (Figure 7A,C), which was clearly different from cell staining through endocytosis (Figure 3B,C). After embryo 
development, populations of daughter cells of the same color code were observed for both 3 and 6 color staining protocols (Figure 6B,D). Again, even for the 6 color protocol, all colors could be readily identified, indicating minimal exchange of the NPs among the cells. These results showed that upon cell division the NPs were equally shared by the daughter cells, leading to a homogeneous, bright staining of all cells derived from a given cell during embryonic morphogenesis. Labelling with our NPs thus provides an easy way of tracing the distribution of cells throughout the whole embryo for several hours and this can be done for at least six cell populations simultaneously.
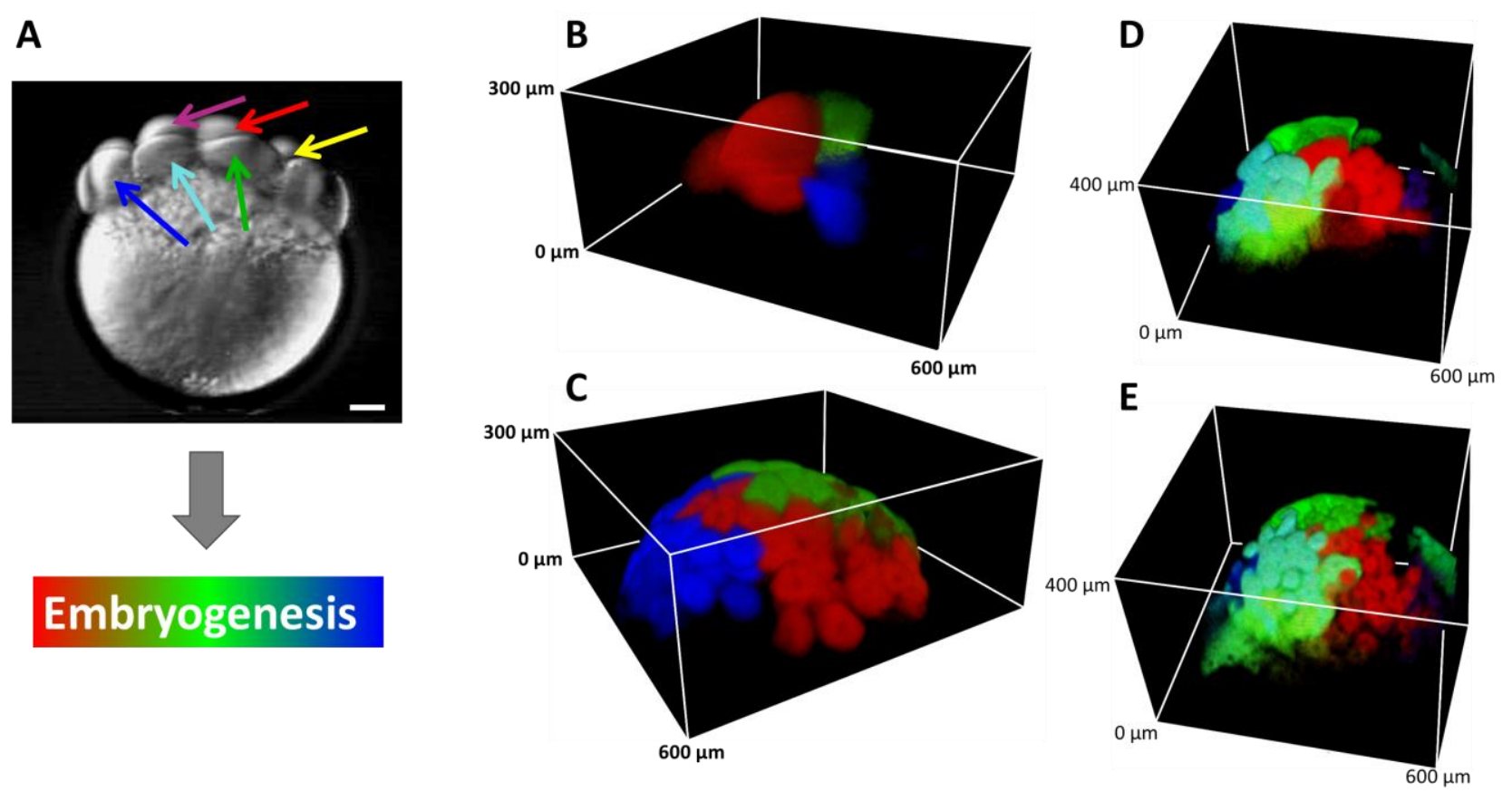

Figure 7. Imaging of the development of zebrafish embryos labeled by intracellular injection of fluorescent NPs. (A) Scheme of experiment: Multiple intracellular injections of NPs into 8 cell stage zebrafish embryos. Transmission image is shown, scale bar $100 \mu \mathrm{m}$. (B) and (C): 3D reconstruction of embryos labeled with, respectively DiO, DiI, and DiD NPs through microinjection inside the cytoplasm of three distinct cells at the 4 cell stage imaged $30 \mathrm{~min}$ after injection (B), and 80 min after injection (C). (D) and (E): 3D reconstruction of embryos labeled with 6 NP mixtures (red: DiD NPs, green: DiI NPs, blue: DiO NPs, cyan: DiO NPs and DiI NPs, magenta: DiD NPs and DiO NPs, yellow: DiD NPs and DiI NPs) through microinjection inside the cytoplasm of six distinct cells at the 8 cell stage imaged 75 min after injection (D), and 135 min after injection (E). 


\section{Discussion and conclusions}

For successful multi-color labeling of cells, we needed fluorescent NPs having three distinct absorption and emission colors, identical sizes and surface properties. To achieve this, we designed polymer NPs loaded with hydrophobic cyanine dyes, DiO, DiI and DiD, corresponding to the most frequently used laser lines. However, encapsulation of these cationic dyes with inorganic counterions (chloride or perchlorate) increased the size of the NPs, probably due to dye adsorption at the particle surface leading to neutralization of the particle negative charge, as we observed earlier with rhodamine derivatives. ${ }^{[20]}$ Remarkably, when these counterions were replaced by bulky hydrophobic counterions, no influence of the dye loading on the size of the NPs was observed. In this case, more hydrophobic dye salts are expected to form, which are better integrated into NPs. The identical size for different colors is a key advantage of our NPs compared to QDs, where color is directly linked to the size of the NPs. ${ }^{[25]}$ Moreover, bulky counterions significantly decreased ACQ of cyanines. F12 performed particularly well, especially for the longest dye DiD, probably because it isolates better the dyes from direct $\pi$-stacking. ${ }^{[26]}$ The F12 counterion thus allowed obtaining QYs of $14 \%$ for DiD at $20 \mathrm{mM}$ loading, in contrast to only $2 \%$ for DID 4chlorobenzenesulfonate ${ }^{[27]}$ and for DiD chloride at the same loading. The use of bulky counterions is probably a generic approach to better encapsulate and prevent ACQ of cationic dyes in polymer NPs, as the concept works for both cyanines and octadecyl rhodamine $\mathrm{B}^{[20]}$. Importantly, single particle measurements suggest that obtained DiI-F12 NPs are $\sim 20$-fold brighter than QDs. Taking into account the expected number of DiI-F12 dyes per NP ( 300), their extinction coefficient of $94000 \mathrm{M}^{-1} \mathrm{~cm}^{-1}$ at $532 \mathrm{~nm}$ excitation and a fluorescence quantum yield of 0.15 , the expected brightness is $300 \times 94000 \times 0.15=4.2 \times 10^{6} \mathrm{M}^{-1} \mathrm{~cm}^{-1}$. For QDs585, the brightness at $532 \mathrm{~nm}$ excitation is $2.1 \times 10^{5} \mathrm{M}^{-1} \mathrm{~cm}^{-1}$, which is 20-fold lower than that of our DiI-F12 NPs. The other two types of NPs should present similar brightness, because of close values of their size, QY and the extinction coefficients of the loaded dyes.

The optimized NPs showed efficient internalization into the cells within $3 \mathrm{~h}$ of incubation. The observed perinuclear localization of NPs in form of dots especially in HeLa and KB cells, together with previous results on rhodamine-loaded PLGA NPs showing their lysosomal localization, ${ }^{[20]}$ suggest an endocytic pathway. As PLGA NPs biodegrade on the time scale of several months, ${ }^{[28]}$ they remain entrapped inside lysosomes similarly to other NPs, ${ }^{[2]}$ which enables their long-term imaging. Moreover, the perinuclear localization of the NPs facilitated greatly the automatic recognition of cells and the analysis of their color codes. 
The simple incubation of cells with our NPs thus led to a bright, homogeneous and long-term labeling of virtually all cells of a given population, and this for all the six different cell types tested. Owing to the same size and surface properties, NPs of three distinct colors exhibit similar internalization, so their mixing in different combinations enabled RGB coding of cells with at least 13 colors. Remarkably, each cell of the population received the same combination of RGB NPs and, therefore, the identical barcode. The behavior of our NPs is different from that reported for QDs, where stochastic combination of color codes was observed for cells within the same population. ${ }^{[16 \mathrm{~b}]}$ Importantly, the color code generated by our NPs can be transmitted through many generations of daughter cells. As every division decreases twice the number of NPs, the method can be used to track cell division, as it is done by the fluorescein-based probe CFSE, ${ }^{[30]}$ but in our case multiple color codes can be used. Finally, multiple populations of cells bearing different RGB barcodes can be co-incubated together for weeks without signs of color mixing. Remarkably, the method works well even for a mixture of 13 barcoded cell populations, showing that it can be readily used to study complex multicellular systems. Although we did not test more than 13 barcodes, it is clear that the method could be further extended to a larger number of color codes.

The long-term color coding by NPs is suitable to study the organization and interactions of different cell types in complex co-cultures as was demonstrated on two examples. First, we showed that up to 6 different cell lines labeled with different colors could be readily distinguished in co-cultures. Second, it enabled monitoring competition within six cell populations differently treated by doxorubicin. Our observations suggest that at very small doxorubicin concentrations, the capacity of the cells to adhere could be similar or even higher than that of non-treated cells, while higher concentrations of the drug inhibit cell adherence. This experiment not only shows the effect of drug on the cell behavior, but it may also reveal the heterogeneous nature of the cells in culture. ${ }^{[31]}$ Indeed, whereas some fraction of the cells was killed by low concentrations $(0.2 \mu \mathrm{M})$ of doxorubicin (Figure S20), the surviving fraction showed excellent adhesion properties. Understanding the reasons for this heterogeneity and distinct adhesion behaviors of the drug-treated cells is outside the scope of this work. However, we showed that it is a powerful method to study multiple cell populations in direct contact and competition and it enables new ways to test drugs, such as high-content screening. ${ }^{[32]}$

The experiments performed in the zebrafish embryo showed that the new methodology of cell labeling allows also multiple applications in vivo. The first one relies on the fast and efficient fluorescent labeling of cells prior to transplantation in vivo to map up to 6 different cell populations and potentially track individual cells. Multi-color labeling of distinct populations of tumor cells should allow fine tracking of single population's behavior, where one could tune gene expression or 
metastatic abilities for example. Such a protocol should be of choice to study invasion and metastasis of pre-labeled tumor cells, and further assess drug resistance using intravital imaging. ${ }^{[33]}$ Second, we showed that NPs can be used to directly label cells in vivo with at least 6 different colors to follow individual cells and cell populations during embryonic development. Intracellular injection of NPs at the early developmental stage proved to be suitable to explore cell behavior in morphogenetic processes in zebrafish embryos and should be useful in other species as well, especially those not amenable to genetic engineering. The high brightness of our NPs and their homogenous distribution in the cytosol after intracellular microinjection ensures high performance in terms of signal to noise ratio and spatial and temporal resolution in large 3D field of views.

Compared to RGB coding of cells by fluorescent proteins, as for instance realized by Brainbow ${ }^{[6]}$, our method, based on fluorescent NPs, presents several important features: i) It does not require genetic modification, ii) it is extremely easy, fast and can in principle operate in any cell type and the brightness of labeling can be tuned much easier compared to fluorescent proteins in rainbowtype animals. The fast labeling without genetic modification is particularly promising to study primary cell cultures. It is also important in early embryogenesis studies, where multiple division cycles take places within hours. ${ }^{[34]}$ In our method, a given cell population bears an identical RGB barcode, whereas Brainbow labeling generates a variety of color codes within the same population. Thus, these two methods are complementary. In the method presented here, cell division leads to a reduction of the number of NPs per cell, which ultimately limits the observation time in rapidly dividing cells (like HeLa). Nevertheless, by optimizing the NPs concentration we could detect labeled HeLa cells for at least 19 days. This is significantly longer than the one week labeling reported earlier for QDs, ${ }^{[5 b]}$ probably because our NPs are much brighter. Moreover, in contrast to the stochastic distribution of colors within the same labeled population using QDs, ${ }^{[16 b]}$ our approach generates a uniform color code within the same population stable throughout multiple generations. Finally, our NP-based method is advantageous over direct cell labeling by dyes (1). Cell trackers work efficiently only for a few days. ${ }^{[12]}$ Encapsulation of dyes inside NPs, on the other hand, prevents dye leakage from cells and prolongs staining for weeks. This feature minimizes the loss of staining and enables co-culture of multiple cell populations with different barcodes with minimized exchange of colors (2). It features homogeneous cell staining, while classical dyes, like DiD or CellVue ${ }^{\circledR}$ Claret (PKH type), provide rather heterogeneous cell staining because of their poor water solubility. ${ }^{[35]}$ Therefore, as we observed in this work, simple mixing of two different dyes (DiI and DiD) does not generate a homogeneous color code within the same cell population. All these points probably explain why organic dyes have never been used to date to generate multiple color codes transmittable to daughter cells. The only examples are limited to color coding of fixed cells. ${ }^{[36]}$ 
Thus, the proposed method of multi-color coding, being complementary to Brainbow, does not have analogues in literature and opens the way to a variety of applications related to long-term cell tracking in vitro and in vivo.

Finally, this work provides new insights for interfacing nanotechnology and biology. Rather than creating complex multimodal nanoparticles bearing simultaneously multiple functions, we propose to implement different functions/modalities (colors in our case) separately into "homologous" nanoparticles of identical size and surface properties. The latter ensure their identical delivery into live cells, where these NPs can then combine forces to perform sophisticated tasks.

\section{Experimental section}

Synthesis of dye salt: DiI-Cl and DiD-Cl were synthesized according to a previously described procedure ${ }^{[37]}$. Synthesis of all ion pairs of cyanine dyes with tetraphenyl borate counterions was done by ion exchange of corresponding dye chloride with a borate salt in dichloromethane followed by purification by column chromatography. The details are described in Supporting Information.

Preparation of fluorescent NPs: PLGA (lactide:glycolide, 1:1, mole:mole, Mn 24000) was dissolved at $2 \mathrm{mg} \mathrm{ml}^{-1}$ in acetonitrile containing different amounts of dye. These solutions were added quickly and under stirring (shaking) using a micropipette to a tenfold volume excess of 20 $\mathrm{mM}$ phosphate buffer at $\mathrm{pH}$ 7.4. The particle solution was then quickly diluted fivefold with the same buffer.

Characterization of NPs: DLS measurements were performed on a Zetasizer Nano series DTS 1060 (Malvern Instruments S.A.). Electron microscopy was performed on Philips CM120 transmission electron microscope. Absorption and emission spectra were recorded on a Cary 400 Scan ultraviolet-visible spectrophotometer (Varian) and FluoroMax-4 spectrofluorometer (Horiba Jobin Yvon) equipped with a thermostated cell compartment, respectively. QYs were calculated using rhodamine $\mathrm{B}$ in methanol ${ }^{1}(\mathrm{QY}=0.7)$ for DiI series, fluorescein in $0.1 \mathrm{M} \mathrm{NaOH}^{2}(\mathrm{QY}=0.92)$ for $\mathrm{DiO}$ series and $\mathrm{DiD}$ in $\mathrm{MeOH}^{3}(\mathrm{QY}=0.33)$ for DiD series.

Cell labeling: For labeling, cells were seeded in 6 well plates at 200000 cells/well (21 000 cells / $\mathrm{cm}^{2}$ ) or at 500000 cells/well in $25 \mathrm{~cm}^{2}$ cell culture flasks (20 000 cells $/ \mathrm{cm}^{2}$ ). After letting the cells adhere for $18 \mathrm{~h}$, the cell culture medium was removed and the cells were rinsed twice with optiMEM, followed by incubation with a freshly prepared solution of the NPs $(0.15 \mathrm{nM}$ in particles, $2.5 \mathrm{~mL}$ for 6 well plates, $10 \mathrm{~mL}$ for $25 \mathrm{~cm}^{2}$ cell culture flasks). NP suspensions for cell labeling were prepared starting from stock solutions in $20 \mathrm{mM}$ phosphate buffer at a $\mathrm{pH}$ of 7.4 with a 
particle concentration of $3 \mathrm{nM}(0.04 \mathrm{~g} / \mathrm{L}$ of polymer). Depending on the desired color the stock solutions were mixed in the needed proportions (e.g. DiO:DiI:DiD 1:0:0 for "blue", or 0.5:0.5:0 for "cyan") and diluted in optiMEM to a concentration of $0.15 \mathrm{nM}(0.002 \mathrm{~g} / \mathrm{L}$ of polymer $)$. After $3 \mathrm{~h}$ of incubation the NP suspension was removed, the cells were rinsed first with optiMEM, then with PBS, and finally with the corresponding cell culture medium.

The resulting cells were then either cultured for longer periods, mixed, or transferred for imaging. For transfer or mixing the wells were rinsed twice with PBS followed by incubation for 2 to $5 \mathrm{~min}$ with $0.4 \mathrm{~mL}$ of trypsin at $37^{\circ} \mathrm{C}$, and collection of the detached cells in $3 \mathrm{~mL}$ of the corresponding medium. After centrifugation and redispersion in 1 to $5 \mathrm{~mL}$ of medium (depending on the obtained number of cells), the cells were counted. For mixing of different cell populations, equal numbers of cells were combined in a centrifugation tube and thoroughly mixed before further use (for example "blue", green", and "red" cells or HeLa, KB, and CHO cells). For imaging, the cells, after the desired labeling, mixing, and time of culture, were seeded in LabTek 8 well plates at 60000 cells/well and left to adhere for at least $18 \mathrm{~h}$.

Confocal microscopy: Fluorescence imaging of the cells in chambered microscope slides (LabTek or Ibidi 8 well plates) was performed on a Leica TSC SPE confocal microscope using either a 20x air objective or a $63 \mathrm{x}$ oil immersion objective. The different channels were recorded as follows: excitation $405 \mathrm{~nm}$, emission recorded from $430 \mathrm{~nm}$ to $480 \mathrm{~nm}$; excitation $488 \mathrm{~nm}$, emission recorded from $495 \mathrm{~nm}$ to $560 \mathrm{~nm}$; excitation $561 \mathrm{~nm}$, emission recorded from $570 \mathrm{~nm}$ to $610 \mathrm{~nm}$; excitation $635 \mathrm{~nm}$, emission recorded from $650 \mathrm{~nm}$ to $750 \mathrm{~nm}$. The power of the $405 \mathrm{~nm}$ laser was adjusted as needed. The power of the 488,561 , and $635 \mathrm{~nm}$ lasers was set either to 10 or to $20 \%$ of the nominal power (same for all three) and the gain and offset were set to the same value for all three. Three successive sequences were recorded for each image.

Image analysis: Image analysis was performed using the Fiji software and, for data analysis, the $\mathrm{R}$ software. The three consecutive images were averaged for each channel. The intensity levels were set to the same levels for the three NP channels for all images presented here. An ImageJ macro was programmed to determine automatically the colors of the individual cells (macro code can be found in the Supporting information). Briefly, the macro combines the intensities from the three NP channels in a single gray scale image. This image is then used to detect the locations of the individual cells and so to create a mask, which allows measuring the intensities of the three channels for each individual cell. The intensities are then normalized to 1 in order to obtain the RGB barcode of each cell. 
Tracking cancer cells in zebrafish embryos: Wild-type Golden zebrafish embryos (48 hours postfertilization (hpf)) were anesthetized in Danieau containing $650 \mu \mathrm{M}$ tricain and mounted in $0.8 \%$ low melting point (LMP) agarose. Meanwhile, unlabeled D2A1 cells (murine mammary carcinoma cells) were cultured in 6-well plates and incubated for $3 \mathrm{~h}$ at $37 \% / 5 \% \mathrm{CO}_{2}$ with $\mathrm{NPs}\left(2 \mathrm{mg} \mathrm{L}^{-1}\right)$ of different color and their one-to-one mixtures (red: DiD NPs, green: DiI NPs, blue: DiO NPs, cyan: DiO NPs and DiI NPs, magenta: DiD NPs and DiO NPs, yellow: DiD NPs and DiI NPs) before being trypsinized. A mixture of RGB barcoded cells at equal quantities was prepared at a concentration of $100 \times 10^{6}$ per ml. Embryos were injected under a stereomicroscope (LEICA M205 FA) equipped with fluorescence module. The mixture of barcoded cells was loaded in a microforged glass capillary and $18 \mathrm{~nL}$ of the mixture was injected in the duct of Cuvier of the embryos using a microinjector (Nanoject, Drummond). Injected embryos were then imaged at $3 \mathrm{~h}$ post-injection using a confocal microscope (Leica TCS SP5, 25X/ON 0.95 N.A. water immersion objective).

Labeling and imaging early zebrafish embryos: Wild-type Danio rerio (zebrafish) embryos were reared and staged as described elsewhere. ${ }^{[34 \mathrm{~b}]}$ Embryos were collected at the one-cell-stage and kept in embryo medium (EM) at $28.5^{\circ} \mathrm{C}$ until the desired stage. ${ }^{[34 a]}$ Intracellular injection at the 4-cell or 8-cell stage were performed into chorionated embryos with solutions of DiO, DiI, and DiD NPs or one-to-one mixtures to generate three or six RGB barcodes (red: DiD NPs, green: DiI NPs, blue: DiO NPs, cyan: DiO NPs and DiI NPs, magenta: DiD NPs and DiO NPs, yellow: DiD NPs and DiI NPs), all at global NP concentrations of $0.2 \mathrm{~g} \mathrm{~L}^{-1}$. The injected volume was about $1 \mathrm{nl}$ per cell. Injected embryos were immediately mounted in a 3-cm Petri dish with a glass coverslip bottom, sealing a hole of $0.5 \mathrm{~mm}$ at the dish centre, where a Teflon tore (ALPHAnov) with a hole of $780 \mu \mathrm{m}$ received the dechorionated embryo. The embryo was maintained and properly oriented (animal pole up) by infiltrating around it $0.5 \%$ low-melting-point agarose (Sigma) in embryo medium as described elsewhere. ${ }^{[34 \mathrm{~b}]} 3 \mathrm{D}+$ time imaging was performed with a Zeiss LSM780 confocal upright microscope with a high NA, water dipping lens objective (either 20x or 25x) for up to 12 hours. Temperature control was achieved with and Okolab chamber $\left(26^{\circ} \mathrm{C}\right.$ in the Petri dish). All the investigations using the zebrafish model were carried out in compliance with the European and international guidelines on animal welfare (Directive 2010/63/EU).

\section{Supporting Information}

Supporting Information is available from the Wiley Online Library or from the author. 
Acknowledgements. This work was supported by the European Research Council ERC Consolidator grant BrightSens 648528. BA was supported by LabEx Chimie des Systèmes Complexes. We thank Y. Mely and P. Didier for providing access to wide-filed fluorescence microscopy and C. Ruhlmann for help with electron microscopy. We thank Romain Vauchelles for help with image analysis using the ImageJ software and Claudine Ebel for help with flow cytometry. We are very much grateful to Francesca PERI (EMBL) and Kerstin RICHTER (EMBL) for providing zebrafish embryos. We thank the BioEmergences platform and FBI ANR-10-INBS-04 for injections and 3D+time imaging.

Received: ((will be filled in by the editorial staff))

Revised: ((will be filled in by the editorial staff))

Published online: ((will be filled in by the editorial staff))

[1] a) J. H. Gao, H. W. Gu, B. Xu, Accounts Chem. Res. 2009, 42, 1097; b) D. E. Lee, H. Koo, I. C. Sun, J. H. Ryu, K. Kim, I. C. Kwon, Chem. Soc. Rev. 2012, 41, 2656; c) N. Lee, D. Yoo, D. Ling, M. H. Cho, T. Hyeon, J. Cheon, Chem. Rev. 2015, 115, 10637; d) S. K. Yen, D. Janczewski, J. L. Lakshmi, S. Bin Dolmanan, S. Tripathy, V. H. B. Ho, V. Vijayaragavan, A. Hariharan, P. Padmanabhan, K. K. Bhakoo, T. Sudhaharan, S. Ahmed, Y. Zhang, S. T. Selvan, ACS Nano 2013, 7, 6796; e) H. M. Kim, H. Lee, K. S. Hong, M. Y. Cho, M. H. Sung, H. Poo, Y. T. Lim, ACS Nano 2011, 5, 8230.

[2] a) E. K. Lim, T. Kim, S. Paik, S. Haam, Y. M. Huh, K. Lee, Chem. Rev. 2015, 115, 327; b) C. M. Spillmann, J. Naciri, W. R. Algar, I. L. Medintz, J. B. Delehanty, ACS Nano 2014, 8, 6986.

[3] a) A. Wagh, F. Jyoti, S. Mallik, S. Qian, E. Leclerc, B. Law, Small 2013, 9, 2129; b) Y. W. C. Cao, R. C. Jin, C. A. Mirkin, Science 2002, 297, 1536; c) G. Wang, Y. K. Leng, H. J. Dou, L. Wang, W. W. Li, X. B. Wang, K. Sun, L. S. Shen, X. L. Yuan, J. Y. Li, J. S. Han, H. S. Xiao, Y. Li, ACS Nano 2013, 7, 471; d) S. Giri, E. A. Sykes, T. L. Jennings, W. C. W. Chan, ACS Nano 2011, 5, 1580.

[4] a) Z. Cheng, A. Al Zaki, J. Z. Hui, V. R. Muzykantov, A. Tsourkas, Science 2012, 338, 903; b) P. D. Howes, R. Chandrawati, M. M. Stevens, Science 2014, 346, 1247390.

[5] a) A. Taylor, K. M. Wilson, P. Murray, D. G. Fernig, R. Levy, Chem. Soc. Rev. 2012, 41, 2707; b) J. K. Jaiswal, H. Mattoussi, J. M. Mauro, S. M. Simon, Nat. Biotechnol. 2003, 21, 47; c) T. J. Wu, Y. K. Tzeng, W. W. Chang, C. A. Cheng, Y. Kuo, C. H. Chien, H. C. Chang, J. Yu, Nat. Nanotechnol. 2013, 8, 682; d) K. M. Dupont, K. Sharma, H. Y. Stevens, J. D. Boerckel, A. J. Garcia, R. E. Guldberg, Proc. Natl. Acad. Sci. U.S.A. 2010, 107, 3305.

[6] a) J. Livet, T. A. Weissman, H. N. Kang, R. W. Draft, J. Lu, R. A. Bennis, J. R. Sanes, J. W. Lichtman, Nature 2007, 450, 56; b) D. Cai, K. B. Cohen, T. Luo, J. W. Lichtman, J. R. Sanes, Nat. Methods 2013, 10, 540.

[7] a) J. P. Card, O. Kobiler, J. McCambridge, S. Ebdlahad, Z. Y. Shan, M. K. Raizada, A. F. Sved, L. W. Enquist, Proc. Natl. Acad. Sci. U.S.A. 2011, 108, 3377; b) D. Hadjieconomou, S. Rotkopf, C. Alexandre, D. M. Bell, B. J. Dickson, I. Salecker, Nat. Methods 2011, 8, 260; c) S. Hampel, P. Chung, C. E. McKellar, D. Hall, L. L. Looger, J. H. Simpson, Nat. Methods 2011, 8, 253.

[8] Y. A. Pan, T. Freundlich, T. A. Weissman, D. Schoppik, X. C. Wang, S. Zimmerman, B. Ciruna, J. R. Sanes, J. W. Lichtman, A. F. Schier, Development 2013, 140, 2835.

[9] N. Di Girolamo, S. Bobba, V. Raviraj, N. C. Delic, I. Slapetova, P. R. Nicovich, G. M. Halliday, D. Wakefield, R. Whan, J. G. Lyons, Stem Cells 2015, 33, 157.

[10] J. W. Wu, R. Turcotte, C. Alt, J. M. Runnels, H. Tsao, C. P. Lin, Sci. Rep. 2016, 6.

[11] C. R. Parish, Immunol. Cell Biol. 1999, 77, 499.

[12] S. K. Lee, M. S. Han, C. H. Tung, Small 2012, 8, 3315.

[13] a) O. S. Wolfbeis, Chem. Soc. Rev. 2015, 44, 4743; b) S. Liu, L. M. Tay, R. Anggara, Y. J. Chuah, Y. Kang, ACS Applied Materials \& Interfaces 2016, 8, 11925. 
[14] a) Y. Yu, C. Feng, Y. Hong, J. Liu, S. Chen, K. M. Ng, K. Q. Luo, B. Z. Tang, Adv. Mater. 2011, 23, 3298; b) D. Ding, D. Mao, K. Li, X. M. Wang, W. Qin, R. R. Liu, D. S. Chiam, N. Tomczak, Z. M. Yang, B. Z. Tang, D. L. Kong, B. Liu, ACS Nano 2014, 8, 12620.

[15] a) S. Rana, N. D. B. Le, R. Mout, K. Saha, G. Y. Tonga, R. E. S. Bain, O. R. Miranda, C. M. Rotello, V. M. Rotello, Nat. Nanotechnol. 2015, 10, 65; b) M. Y. Han, X. H. Gao, J. Z. Su, S. Nie, Nat. Biotechnol. 2001, 19, 631; c) K. Ming, J. Kim, M. J. Biondi, A. Syed, K. Chen, A. Lam, M. Ostrowski, A. Rebbapragada, J. J. Feld, W. C. W. Chan, ACS Nano 2015, 9, 3060.

[16] a) L. C. Mattheakis, J. M. Dias, Y. J. Choi, J. Gong, M. P. Bruchez, J. Q. Liu, E. Wang, Anal. Biochem. 2004, 327, 200; b) P. Rees, J. W. Wills, M. R. Brown, J. Tonkin, M. D. Holton, N. Hondow, A. P. Brown, R. Brydson, V. Millar, A. E. Carpenter, H. D. Summers, Nat. Methods 2014, $11,1177$.

[17] H. D. Summers, P. Rees, M. D. Holton, M. R. Brown, S. C. Chappell, P. J. Smith, R. J. Errington, Nat. Nanotechnol. 2011, 6, 170.

[18] a) K. Li, B. Liu, Chem. Soc. Rev. 2014, 43, 6570; b) A. Reisch, A. S. Klymchenko, Small 2016, 12, 1968.

[19] a) J. Chen, P. Zhang, G. Fang, P. Yi, F. Zeng, S. Wu, The Journal of Physical Chemistry B 2012, 116, 4354; b) J. Chen, F. Huang, H. Wang, Y. Li, S. Liu, P. Yi, Journal of Applied Polymer Science 2015, 132, 41492.

[20] A. Reisch, P. Didier, L. Richert, S. Oncul, Y. Arntz, Y. Mely, A. S. Klymchenko, Nat. Commun. 2014, 5, 4089.

[21] A. Reisch, A. Runser, Y. Arntz, Y. Mély, A. S. Klymchenko, ACS Nano 2015, 9, 5104.

[22] a) M. Cametti, B. Crousse, P. Metrangolo, R. Milani, G. Resnati, Chem. Soc. Rev. 2012, 41, 31; b) I. T. Horváth, Acc. Chem. Res. 1998, 31, 641.

[23] Y. N. Hong, J. W. Y. Lam, B. Z. Tang, Chem. Soc. Rev. 2011, 40, 5361.

[24] R. Kreder, S. Oncul, O. A. Kucherak, K. A. Pyrshev, E. Real, Y. Mely, A. S. Klymchenko, RSC Adv. 2015, 5, 22899.

[25] a) A. P. Alivisatos, Science 1996, 271, 933; b) I. L. Medintz, H. T. Uyeda, E. R. Goldman, H. Mattoussi, Nat. Mater. 2005, 4, 435.

[26] I. Shulov, S. Oncul, A. Reisch, Y. Arntz, M. Collot, Y. Mely, A. S. Klymchenko, Nanoscale 2015, 7, 18198.

[27] A. Wagh, S. Y. Qian, B. Law, Bioconjugate Chem. 2012, 23, 981.

[28] N. Samadi, A. Abbadessa, A. Di Stefano, C. F. van Nostrum, T. Vermonden, S. Rahimian, E. A. Teunissen, M. J. van Steenbergen, M. Amidi, W. E. Hennink, J Control Release 2013, 172, 436.

[29] G. Sahay, D. Y. Alakhova, A. V. Kabanov, J. Control. Release 2010, 145, 182.

[30] A. B. Lyons, C. R. Parish, J. Immunol. Meth. 1994, 171, 131.

[31] a) B. Snijder, R. Sacher, P. Ramo, E. M. Damm, P. Liberali, L. Pelkmans, Nature 2009, 461, 520; b) B. Snijder, L. Pelkmans, Nat. Rev. Mol. Cell Biol. 2011, 12, 119.

[32] F. Zanella, J. B. Lorens, W. Link, Trends Biotechnol. 2010, 28, 237.

[33] R. White, K. Rose, L. Zon, Nat. Rev. Cancer 2013, 13, 624.

[34] a) C. B. Kimmel, W. W. Ballard, S. R. Kimmel, B. Ullmann, T. F. Schilling, Dev. Dyn. 1995, 203, 253; b) E. Faure, T. Savy, B. Rizzi, C. Melani, O. Stasova, D. Fabreges, R. Spir, M. Hammons, R. Cunderlik, G. Recher, B. Lombardot, L. Duloquin, I. Colin, J. Kollar, S. Desnoulez, P. Affaticati, B. Maury, A. Boyreau, J. Y. Nief, P. Calvat, P. Vernier, M. Frain, G. Lutfalla, Y. Kergosien, P. Suret, M. Remesikova, R. Doursat, A. Sarti, K. Mikula, N. Peyrieras, P. Bourgine, Nat. Commun. 2016, 7 , 8674.

[35] M. Collot, R. Kreder, A. L. Tatarets, L. D. Patsenker, Y. Mely, A. S. Klymchenko, Chem. Commun. 2015, 51, 17136.

[36] P. O. Krutzik, G. P. Nolan, Nat. Methods 2006, 3, 361.

[37] X. J. Peng, Z. G. Yang, J. Y. Wang, J. L. Fan, Y. X. He, F. L. Song, B. S. Wang, S. G. Sun, J. L. Qu, J. Qi, M. Yang, J. Am. Chem. Soc. 2011, 133, 6626. 


\section{The table of contents entry:}

Structurally close but spectrally distinct fluorescent polymer nanoparticles are prepared through loading of cyanine dyes with help of bulky hydrophobic counterions, preventing aggregation-caused quenching. Due to identical internalization, these nanoparticles can be combined together for long-term labeling and tracking of cells in vitro and in vivo with at least 13 color codes.

Bohdan Andreiuk, Andreas Reisch*, Marion Lindecker, Gautier Follain, Nadine Peyriéras, Jacky G. Goetz, Andrey S. Klymchenko*

Fluorescent Polymer Nanoparticles for Cell Barcoding in Vitro and in Vivo

ToC figure

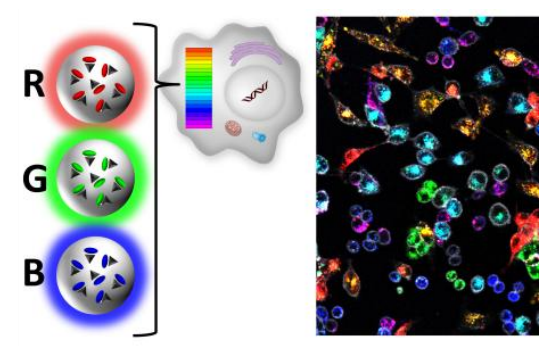

